FORAMS 2006

\title{
Deep-sea benthic foraminifera and the oceanic carbon cycle during the Cenozoic
}

\author{
Ellen Thomas \\ Department of Geology \& Geophysics, Yale University, New Haven, \\ CT 06520-8109,U.S.A. ellen.thomas@yale.edu
}

Deep-sea benthic foraminifera live in the largest habitat on Earth, constitute an important part of its benthic biomass and form diverse assemblages with common cosmopolitan species. Their assemblages are influenced by a combination of parameters varying at different temporal and spatial scales, in many instances not independent from each other. These parameters include bathymetry, organic matter flux (including lateral influx), oxygen concentrations in bottom and pore waters, location and motion of redox fronts (with their populations of Archaea and Bacteria) through the sediments, sediment grain size, temperature, bottom water chemistry, hydrography (e.g., current flow), hydrostatic pressure, and more difficult to quantify parameters such as seasonality of the flux of organic matter, and relative amounts of labile and refractory organic matter. Food input is seen as important because the deepocean environment is severely food-limited. Benthic foraminiferal assemblages are thus thought to be strongly influenced by events affecting what has been considered to be their main food source, phytoplankton produced by photosynthesis in the photic zone of the surface waters (bentho-pelagic coupling). The energy budget of deep-sea marine ecosystems is, however, being reevaluated in the light of discoveries that there is a discrepancy between measured fluxes of sinking particulate organic matter and sediment community oxygen consumption (faunas apparently consuming more food than supplied), uncertainty about the transport process of organic matter from the surface to the sea floor, and greatly increased estimates of prokaryote standing stock as well as the importance of chemo-autotrophic primary production at mid-water depths and within the sediments. There are, however, as yet no models for the oceanic carbon cycle including prokaryote reservoirs and fluxes, and we do not know how important prokaryote-fixed organic matter is for benthic foraminifera as compared to phytodetritus. The fact that benthic foraminiferal communities close to cold seeps and hydrothermal do not significantly differ from those in regions with high photosynthetic productivity strongly suggests that benthic foraminifera do use bacterial food. In the present oceans, however, 
there is solid evidence for bentho-pelagic coupling, suggesting that in most settings photosynthetic phytoplankton is a more important food source than various prokaryotes. This could, however, be a relatively recent situation, in existence since there are polar ice caps and cold deep oceans. Bentho-pelagic coupling may have been less strong in the oceans of the Cretaceous and Paleogene, which were warmer than the present oceans by $10-12^{\circ} \mathrm{C}$, and where bacterial metabolic rates were thus much faster. A more important role for a bacterial food supply (whether produced photosynthetically or chemosynthetically) could well explain the observation that benthic foraminifera did not suffer significant extinction at the end of the Cretaceous, when phytoplankton communities underwent severe extinction. The severe deepsea benthic foraminiferal extinction (30-50\% of species) at the end of the Paleocene, when planktic organisms show rapid evolutionary turnover, but no major extinction, is presently not well explained. Net extinction rates were similar globally, but there is no independent evidence for global anoxia or dysoxia, or of globally consistent increase or decrease in productivity or carbonate dissolution. The extinction might be linked to a global feature of the endPaleocene environmental change, i.e., rapid global warming, which caused restructuring of deep-sea food webs as a result of increasing metabolic rates and thus energy requirements. Cenozoic deep-sea benthic faunas show gradual faunal turnover during periods of pronounced cooling and increase in polar ice volume: the late Eocene-early Oligocene, the middle Miocene and the middle Pleistocene, when taxa that decreased in abundance during the earlier two turnovers became extinct. The Eocene-Oligocene was the most extensive of these turnovers: bentho-pelagic coupling may have become established at that time, and the importance of a bacterial food supply relative to a supply of rapidly deposited phytodetritus may have decreased during each of these periods of turnover, with decreasing deep-sea temperatures (thus bacterial metabolic rates) and increased surface productivity. 